\title{
Preliminary Study on Catalytic Combustion-type Sensor for Diesel Particulate Matter Detection
}

\author{
Yasutake Teraoka $^{1}$, Cheol-Beom Lim ${ }^{1}$, Hisahiro Einaga ${ }^{1}$, and Yoshihiko Sadaoka ${ }^{2}$ \\ ${ }^{1}$ Department of Energy and Material Sciences, Faculty of Engineering Sciences, Kyushu University, \\ Kasuga, Fukuoka 816-8580, Japan \\ teraoka.yasutake.329@m.kyushu-u.ac.jp \\ ${ }^{2}$ Department of Materials Science and Biotechnology, Graduate School of Science and Engineering, \\ Ehime University, 3 Bunkyo-cho, Matsuyama, Ehime, 790-8577, Japan
}

\begin{abstract}
:
$\mathrm{Ag} / \mathrm{TiO}_{2}$ and $\mathrm{Pt} / \mathrm{TiO}_{2}$ catalysts were active for combustion of soot above $500{ }^{\circ} \mathrm{C}$ and for soluble organic fraction (SOF) below $200{ }^{\circ} \mathrm{C}$, respectively. Sensing characteristics of catalytic combustion-type sensors coated with these catalysts against diesel particulate matter (PM), especially selective sensing of soluble organic fraction (SOF) and soot, were evaluated by the programmed heating of the $\mathrm{PM}$-loaded sensing elements. The $\mathrm{Pt} / \mathrm{TiO}_{2}$ coated sensing element gave the signal due to SOF oxidation around $150-200{ }^{\circ} \mathrm{C}$, while the selective detection of soot was possible with the $\mathrm{Ag} / \mathrm{TiO}{ }_{2}$ coated sensor. Results obtained here strongly suggest the possibilities to construct the catalytic combustion-type PM sensor and to selectively detect SOF and soot by the proper selection of the catalytic materials and operation temperatures.
\end{abstract}

Key words: Catalytic combustion-type sensor, Diesel particulate matter (PM), Soluble organic fraction (SOF), Selective detection of soot and SOF

\section{Introduction}

Diesel particulate filter (DPF) loaded with a catalyst system is regarded as the most effective and promising technology to control emission of particulate matter (PM) which contains soot and soluble organic fraction (SOF) as combustible substances. In order to guarantee the efficient and stable operation of the diesel engine system with the DPF aftertreatment, onboard PM monitoring technology is indispensable. PM sensors so far proposed are physical sensors based on optical [1-4], electrical resistance [5-8] and radio-frequency [9] methods as well as an electrochemical device consisting of a proton-conductor and $\mathrm{Pt}$ electrodes $[11,12]$. The purposes of the present study are to reveal the possibilities of PM detection by the catalytic combustion-type sensor and selective detection of soot and SOF by the proper selection of the catalytic materials and operation temperatures.

The principle of the catalytic combustion-type PM sensor is shown schematically in Fig. 1. Solid PM comes flying on the exhaust gas stream and lands on the surface of the sensor element. When the surface of the element is active enough to oxidize PM at the operating temperature, the temperature of the element increases by the heat of combustion and the temperature increase is detected by the resistivity change of a $\mathrm{Pt}$ wire incorporated in the body of the element. In addition, if we use catalysts and/or operation temperatures which can separately oxidize SOF and soot, selective detection of SOF and soot is possible.

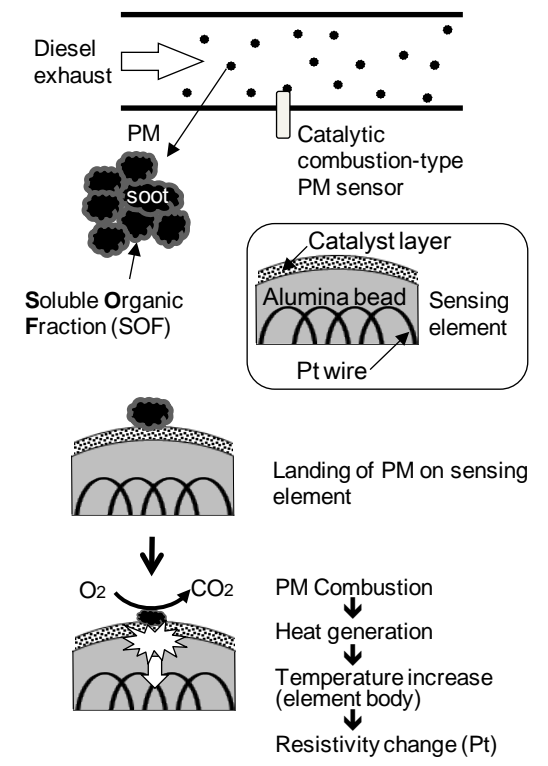

Fig. 1. Principle of catalytic combustion-type PM sensor. 


\section{Experimental}

Two $\mathrm{TiO}_{2}$ supported catalysts, $5 \mathrm{wt} \% \mathrm{Pt} / \mathrm{TiO}_{2}$ and $5 \mathrm{wt} \% \mathrm{Ag} / \mathrm{TiO}_{2}$, were prepared by an ordinary impregnation method and calcination in air at $700{ }^{\circ} \mathrm{C}$ for $5 \mathrm{~h}$ from $\mathrm{TiO}_{2}$ (Reference Catalyst of Catalysis Society of Japan, JRCTIO-4), diammine dinitro platinum (II) (Kojima Chemicals, $\mathrm{HNO}_{3}$ solution) and silver nitrate (Kishida Chemical). XRD measurements revealed that the catalysts contained rutile $\mathrm{TiO}_{2}$ and a metallic form of $\mathrm{Ag}$ and $\mathrm{Pt}$. Specific surface areas measured by the BET method (BELSORP-mini, BEL JAPAN, Inc.) were 9.8 and $7.2 \mathrm{~m}^{2} \mathrm{~g}^{-1}$ for $\mathrm{Pt} / \mathrm{TiO}_{2}$ and $\mathrm{Ag} / \mathrm{TiO}_{2}$, respectively. Carbon black (CB, Sigma-Aldrich) and hexadecane were used as substitutes for soot and SOF, respectively. Simulated PM was prepared by liquid-phase adsorption of hexadecane on CB in n-hexane [12].

PM oxidation reaction was measured by TGDTA. Catalysts and simulated PM (ca. 5wt\%) were mixed by spatula carefully for $10 \mathrm{~min}$, and the mixture was heated at a rate of $10{ }^{\circ} \mathrm{C} \mathrm{min}^{-1}$ from $30{ }^{\circ} \mathrm{C}$ to $800{ }^{\circ} \mathrm{C}$ in a flow of synthetic air $\left(21 \% \mathrm{O}_{2}\right.$ and $\left.79 \% \mathrm{~N}_{2}, 100 \mathrm{~mL} \mathrm{~min}^{-1}\right)$.

A bead of $\gamma-\mathrm{Al}_{2} \mathrm{O}_{3}$ with a diameter of about 1.5 $\mathrm{mm}$, which was fabricated on a coiled Pt wire heater, was used as base structures of the sensing and compensating elements. A coating paste of the catalyst was prepared by mixing $0.2 \mathrm{~g}$ of the catalyst with $1.0 \mathrm{~g}$ of $\alpha$-Terpineol as a binder (nacalai tesque, $\mathrm{C}_{10} \mathrm{H}_{18} \mathrm{O}$ ) by a mixer (LMS, VTX-3000L) for $30 \mathrm{~min}$. The coating paste was applied on the surface of the alumina bead by handwork with a paintbrush so as for the paste to uniformly cover the alumina bead, and then the element was heated at $600{ }^{\circ} \mathrm{C}$ for $2 \mathrm{~h}$ in air by the internal $\mathrm{Pt}$ heater in order to remove the binder and stabilize the sensing element.

Because of the difficulty in preparing the simulated diesel exhaust containing solid PM, model experiments were designed: PM was pre-loaded on the sensing element, and sensing performances were measured under the programmed heating condition in air. Pastes with CB (0.05 g (S), $0.030 \mathrm{~g}(\mathrm{H}), 0.015 \mathrm{~g}(\mathrm{M})$, $0.005 \mathrm{~g}(\mathrm{~L}))$ and $\alpha$-Terpineol (1.0 g (S), $1.2 \mathrm{~g}(\mathrm{~L}$, $M, H)$ ) was prepared by the method same as the preparation of the catalyst paste. The $C B$ layer was formed on the catalyst layer (CBloaded sensing element) by the handapplication of the $C B$ paste on the sensing element and the subsequent heat-treatment at $200{ }^{\circ} \mathrm{C}$ for $1 \mathrm{~h}$ in air by the internal $\mathrm{Pt}$ heater to remove the binder. To prepare the PM-loaded sensing element, hexadecane was dropped on the surface of the CB-loaded sensing element (S) as uniform as possible.

As shown in Fig. 2, the PM-loaded elements with (sensing element) and without (compensating element) the catalyst layer were placed in a sensor chamber, and the potential difference between two elements was used as a sensor signal which was derived from a bridge circuit. Gas flow rate was $100 \mathrm{ml} \mathrm{min}^{-1}$. In the programmed heating method under flowing synthetic air, the elements were heated from 150 to $600{ }^{\circ} \mathrm{C}$ with an interval of $50{ }^{\circ} \mathrm{C}$; the temperature of the elements was kept constant for $5 \mathrm{~min}$ at each measuring temperature.

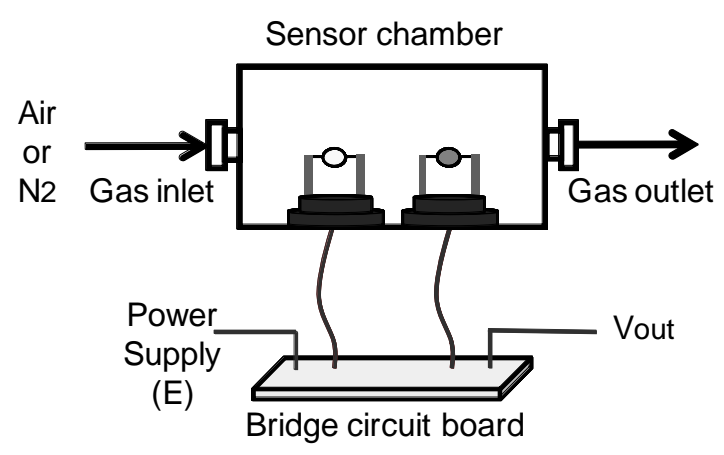

Fig. 2. Measuring system for catalytic combustiontype PM sensor.

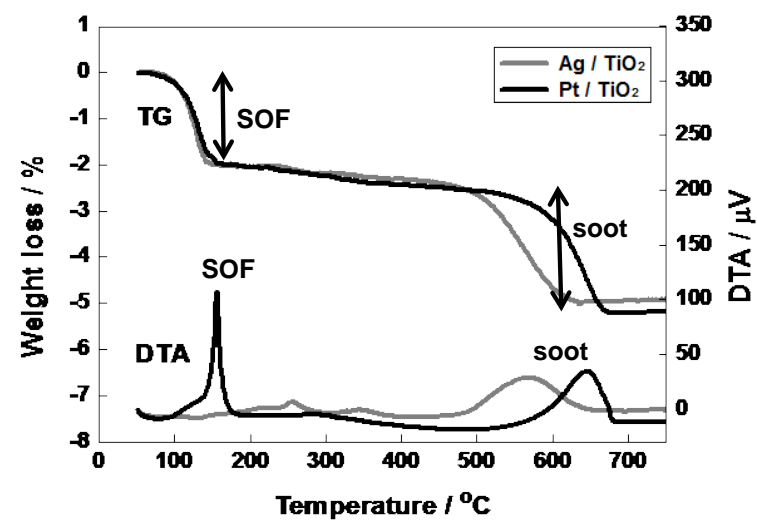

Fig. 3. TG and DTA curves of simulated $P M$ with $\mathrm{Pt} / \mathrm{TiO} 2$ and $\mathrm{Ag} / \mathrm{TiO}_{2}$ catalysts.

\section{Results and Discussion}

The development of catalysts which selectively oxidize soot and SOF is a key issue for the realization of the catalytic combustion-type PM sensor. Fig. 3 shows the oxidation of simulated $\mathrm{PM}$ with $\mathrm{Pt} / \mathrm{TiO}_{2}$ and $\mathrm{Ag} / \mathrm{TiO}_{2}$ catalysts measured by TG-DTA. Weight loss was clearly divided into two steps; the first step with ca. 2 wt $\%$ loss below $200{ }^{\circ} \mathrm{C}$ is originated from SOF combustion and the second one with ca. $3 \mathrm{wt} \%$ loss above $450{ }^{\circ} \mathrm{C}$ is originated from soot combustion. The temperature range of the first weight loss was almost the same for the two catalysts, but an exothermic peak appeared 
with $\mathrm{Pt} / \mathrm{TiO}_{2}$ but not with $\mathrm{Ag} / \mathrm{TiO}_{2}$, indicating that the SOF in simulated PM was oxidized on $\mathrm{Pt} / \mathrm{TiO}_{2}$ but it desorbed (evaporated) from the $\mathrm{Ag} / \mathrm{TiO}_{2}$ catalyst before undergoing oxidation. These results indicate that $\mathrm{Pt}$ is more active for SOF oxidation than $\mathrm{Ag}$. Weight losses in the second step were accompanied with exothermic peaks, which is a sign of the occurrence of soot oxidation. The weight loss with $\mathrm{Ag} / \mathrm{TiO}_{2}$ occurred at lower temperature region than that with $\mathrm{Pt} / \mathrm{TiO}_{2}$, indicating that the former is more active for soot oxidation than the latter. There results indicate that $\mathrm{Pt}$ is more active than $\mathrm{Ag}$ for the SOF oxidation and that the reverse is true for the soot oxidation. Since the soot oxidation temperature with $\mathrm{Pt} / \mathrm{TiO}_{2}$ is comparable to that without a catalyst, $\mathrm{Pt} / \mathrm{TiO}_{2}$ is almost inactive for soot oxidation.

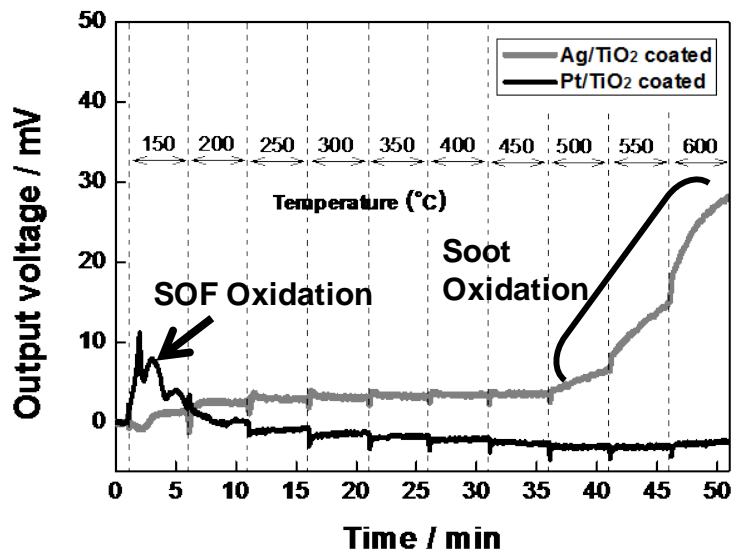

Fig. 4. $P M$ sensing characteristics of $P M$-loaded sensing element $\mathrm{H}$ coated with $\mathrm{Pt} / \mathrm{TiO}_{2}$ and $\mathrm{Ag} / \mathrm{TiO}_{2}$ catalysts.

Fig. 4 shows temperature dependences of the output voltage of sensors with $\mathrm{Ag} / \mathrm{TiO}_{2}$ and $\mathrm{Pt} / \mathrm{TiO}_{2}$ catalysts. PM-loaded sensing element and the compensating element were heated stepwise from $150{ }^{\circ} \mathrm{C}$ to $600{ }^{\circ} \mathrm{C}$ under flowing air; the temperature of the elements was kept constant for $5 \mathrm{~min}$ at each measuring temperature. Although heating program used in Fig. 4 is different from that with the constant heating rate in TG-DTA measurements (Fig. 3), both results reflect the temperature dependence of PM oxidation. The obvious signal from the $\mathrm{Pt} / \mathrm{TiO}_{2}-$ and $\mathrm{Ag} / \mathrm{TiO}_{2}$-coated sensors were observed at $150{ }^{\circ} \mathrm{C}$ and above $500{ }^{\circ} \mathrm{C}$, respectively. By referencing the catalytic activity results (Fig. 3), it can be concluded that $\mathrm{Pt} / \mathrm{TiO}_{2}{ }^{-}$and $\mathrm{Ag} / \mathrm{TiO}_{2}$-coated sensors are sensitive selectively to SOF and soot, respectively. These results strongly suggest the possibilities to construct the catalytic combustion-type PM sensor and to selectively detect SOF and soot by the proper selection of the catalytic materials and operation temperatures [13].
The effect of pre-loading amount of CB on sensing performance was investigated using $\mathrm{Ag} / \mathrm{TiO}_{2}$-coated elements (Fig. 5); the weight ratio of per-loaded PM was $\mathrm{L}: \mathrm{M}: \mathrm{H} \approx 1: 3: 6$. Sensor signals were observed above $500{ }^{\circ} \mathrm{C}$, and the magnitude of the signal at each temperature increased with increasing the preloading amount of $\mathrm{CB}$ as $\mathrm{L}<\mathrm{M}<\mathrm{H}$. If one assumes that the oxidation of $C B$ does not proceed below $450{ }^{\circ} \mathrm{C}$, the amount of $\mathrm{CB}$ on sensing elements is in the ratio of 1:3:6 only when the temperature of the elements reaches $500{ }^{\circ} \mathrm{C}$. The ratio of the output voltage at $23 \mathrm{~min}$ (3 min after reaching $500{ }^{\circ} \mathrm{C}$ ) was $1(\mathrm{~L}): 1.3(\mathrm{M})$ : 1.6(H), which is far from the ratio of the preloaded amount of CB. At $500{ }^{\circ} \mathrm{C}$, output voltages increased almost linearly with time for all the elements, indicating that the oxidation of CB did not reach the stead-state within $5 \mathrm{~min}$. These results indicate the poor quantitativeness and slow response in PM detection [14].

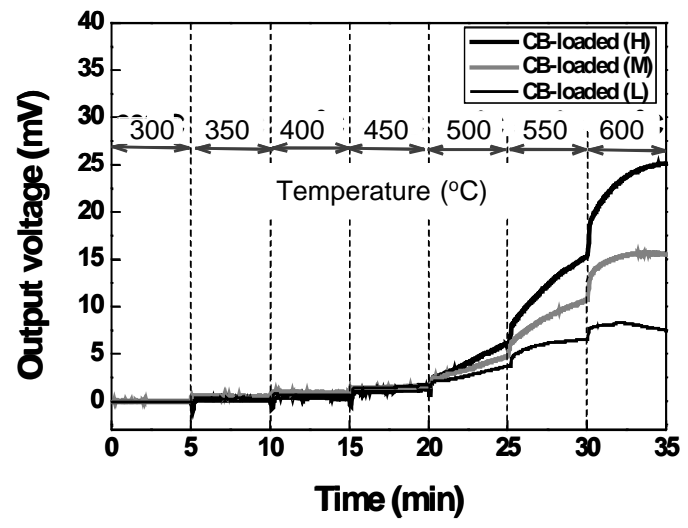

Fig. 5. $P M$ sensing characteristics of $C B$-loaded sensing element $L, M$ and $\mathrm{H}$ coated with $\mathrm{Ag} / \mathrm{TiO} \mathrm{O}_{2}$ catalyst.

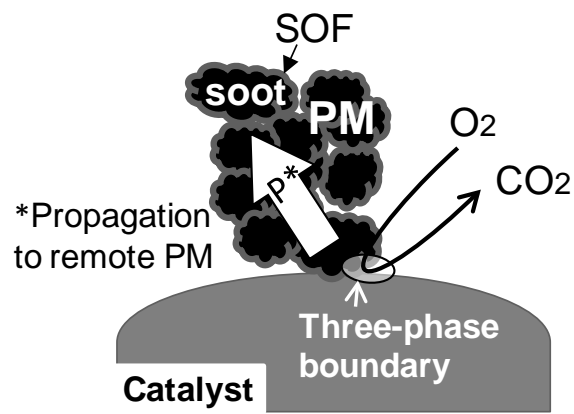

Fig. 6. Catalytic oxidation of PM at the three-phase boundary.

For the conventional combustion-type sensor to detect gaseous molecules, the combustion of the target molecule proceeds on the surface of the sensor element, so that the heat generated by the combustion would be effectively conducted to the element body to give the sensor signal. In contrast, the oxidation of solid PM by a solid catalyst is complicated (Fig. 6). 
Catalytic oxidation of $\mathrm{PM}$ is a three-phase reaction between a gaseous reactant $\left(\mathrm{O}_{2}\right)$, a solid reactant $(P M)$ and a solid catalyst. Since PM lands on the catalyst surface from the exhaust flow by the multi-layer deposition, only tiny parts of the first-layer PM can contact with the catalyst surface. This means that the fraction of the three-phase boundary at which the catalytic reaction occurs is a little as compared with the total volume of the trapped $P M$, and the propagation of the reaction to the $\mathrm{PM}$ remote from the boundary is necessary to combust a majority of deposited PM. It is probable that the catalytic oxidation of $\mathrm{PM}$, which proceeds in the vicinity of the catalyst surface, contributes instantaneously to the heating of the sensing element. With progress of the oxidation toward remote $P M$, the efficiency of the transfer of the combustion heat to the element might decrease. In addition, the rate of combustion seems to be high for the PM near the three-phase boundary by the action of the catalyst and low for the PM remote from the catalyst. The un-uniformity of the PM combustion in the deposited layer should make the PM sensing complicated, and this must be a reason for the poor quantitativeness and slow response in PM detection. If the deposited amount of PM is enough low in order for the PM oxidation to proceed uniformly in the deposited layer and the deposited amount is proportional to the PM concentration in the exhaust, the quantitative detection of PM might be possible by the combustion-type sensor.

\section{Conclusions}

Results obtained in the preliminary investigation surely suggest the possibilities to construct the catalytic combustion-type PM sensor and to selectively detect SOF and soot by the proper selection of the catalytic materials and operation temperatures. While the present results showed the possible dependence of the sensor signal on the amount of SOF and soot, issues to be investigated for the development of the catalytic combustion-type PM sensor have been clarified. The enhancement of the oxidation rate of the solid PM on the surface of the sensor elements is a key issue for the realization of combustion-type PM sensor with quantitativeness and reasonable response time. It should be necessary to investigate in more details from the aspects of the increasing contact between the catalyst and the PM landed on the sensing element.

\section{References}

[1] C.D. Litton, Fire Saf. J., 37, 409 (2002).

[2] C.D. Litton, Fire Saf. J., 44, 387 (2009).

[3] A. Keller, M. Rüegg, M. Forster, M. Loepfe, R. Pleisch, P. Nebiker, H. Burtscher, Sens. Actuators B, 104, 1 (2005).

[4] J.J. Murphy, C.R. Shaddix, Combust. Flame, 143, 1 (2005).

[5] T. Nakata, H. Akita, K. Saguchi, K, Kunimatsu, JP Patent 2,001,041,925.

[6] H. Scheer, H.J. Renz, S. Roesch, H. Koehnlein, B. Gaertner, I. Gerner, DE Patent $102,006,032,741$.

[7] G. Hagen, C. Feistkorn, S. Wiegärtner, A. Heinrich, D. Brüggemann, R. Moos, Sensors, 10, 1589 (2010).

[8] D. Lutic, J. Pagels, R. Bjorklund, P. Josza, J.H Visser, A.W. Grant, M.L. Johansson, J. Paaso, P.-E. Pagerman, M.Sanati, A.L. Spetz, J. Sens., 2010, 1 (2010).

[9] J. Parks II, V. Prikhodko, SAE 10FFL-0238, 2010.

[10] S. Teranishi, K. Kondo, A. Tsuge, T. Hibino, Sens. Actuators B, 140, 170 (2009).

[11] Y. Shen, T. Takeuchi, S. Teranishi, T. Hibino, Sens. Actuators B, 145, 708 (2010).

[12] C.-B. Lim, H. Kusaba, H. Einaga, Y. Teraoka, Catal. Today, 175, 106-111 (2011); doi:10.1016/j.cattod.2011.03.062.

[13] C.-B. Lim, H. Kusaba, H. Einaga, Y. Teraoka, Sens. Actuators B, 160, 463-470 (2011); doi: 10.1016/j.snb.2011.08.009.

[14] C.-B. Lim, H. Kusaba, H. Einaga, Y. Teraoka, J. Novel Carbon Resources Sci., 4, 1-7 (2011). 